\title{
Pembuatan Sistem Informasi Kehadiran Pegawai Non-PNS Berbasis Web Pada Pusat Pelayanan Teknologi (Pusyantek) BPPT
}

\section{(Building Attendance Web-Based Information System for Non Civil Servant at Center for Technology Service (Pusyantek) BPPT)}

\author{
Rachma Fauziah Krismayanti ${ }^{1}$, Sri Nurdiati ${ }^{2}$, Agung Widyo Utomo ${ }^{3}$ \\ ${ }^{1}$ Sekolah Vokasi Institut Pertanian Bogor, Jl. Kumbang No. 14, Bogor, Indonesia \\ 2 \\ Universitas IPB, JI. Raya Dramaga Kampus IPB Dramaga, Bogor, Indonesia \\ 3 \\ Pusat Pelayanan Teknologi BPPT, JI. MH Thamrin No. 8, Jakarta Pusat, Indonesia
}

Email : rachmafrau@gmaill.com

\begin{abstract}
Center for Technology Service (Pusyantek) in Agency for The Assesment and Application of Technology (BPPT) has two kinds of employee, there are civil and non-civil servants. The civil servants already have the official website for attendance system, but the non-civil servants don't have the official website. The presence process for employee has engaged by the fingerprint machine, but still need help from Microsoft Excel. Administrator creates a recapitulation constantly for a period. This process can cause an inacurate data, inefficient time management, and others. Employees also hard to check the presence's datas and complete the absences. With such problems, administrator needs attendance system that can help administrator and non-civil servants. The system was built by incremental method because the client already know requirements that the system necessary. Incremental method consist of five steps, those are communication, planning, modelling, construction, and deployment. System building involved two users, admin and employee. The system building engage by two iteration, which is first increment with 22 functions and second increment with 28 functions. System building successfully implemented attendance data management feature, attendance feature, filling permit's data feature, and filling leave's data feature.

Key words: incremental method, attendance information system, BPPT, Pusyantek
\end{abstract}

\section{ABSTRAK}

Badan Pengkajian dan Penerapan Teknologi (BPPT) khususnya di Pusat Pelayanan Teknologi (Pusyantek) memiliki tenaga kerja yang terdiri atas pegawai PNS dan non-PNS. Pegawai PNS sudah memiliki web resmi untuk sistem kehadiran, namun pegawai non-PNS belum memiliki. Proses kehadiran sudah dilakukan dengan mesin fingerprint, namun pengolahannya masih dilakukan secara manual menggunakan bantuan aplikasi Microsoft Excel. Pengolah melakukan pengolahan untuk menghasilkan rekap secara berkala per periodenya. Hal tersebut bisa menyebabkan data yang tidak akurat, pemanfaatan waktu yang tidak efisien, dan lain-lain. Pegawai pun sulit untuk melihat data kehadiran dan melengkapi data ketidakhadiran. Dengan adanya 
permasalahan tersebut, pengolah mengharapkan adanya sistem kehadiran berbasis web yang memudahkan pengolah dan pegawai non-PNS Pusyantek. Sistem dibuat dengan menerapkan alur kerja yang terstruktur dari metode pengembangan incremental. Metode tersebut digunakan karena klien sudah mengetahui kebutuhan apa saja yang diperlukan. Metode incremental terdiri atas lima tahapan, yaitu komunikasi, perencanaan, pemodelan, pembuatan, serta penyebaran dan umpan balik. Pembuatan sistem melibatkan dua user, yaitu admin dan pegawai. Pembuatan sistem menghasilkan dua kali iterasi yaitu increment pertama dengan 22 fungsi dan increment kedua dengan 28 fungsi. Pembuatan sistem berhasil mengimplementasikan fitur pengelolaan data kehadiran, fitur kehadiran, fitur kelengkapan data pengajuan izin, dan fitur kelengkapan data pengajuan cuti.

Kata kunci : metode incremental, sistem informasi kehadiran, BPPT, Pusyantek

\section{PENDAHULUAN}

Badan Pengkajian dan Penerapan Teknologi (BPPT), tepatnya di Pusat Pelayanan Teknologi (Pusyantek) adalah unit utama yang memiliki peran dalam bidang teknologi. Saat ini, kebutuhan sistem berbasis website semakin meningkat. Sistem informasi berbasis web menjadi pilihan bagi perusahaan sebagai wadah pelayanan untuk kebutuhan internal maupun eksternal.

Badan Pengkajian dan Penerapan Teknologi (BPPT), khususnya pada Pusat Pelayanan Teknologi (Pusyantek) memiliki sumber daya manusia yang memadai. Pegawai di Pusyantek terdiri atas pegawai PNS dan non-PNS. Pegawai PNS Pusyantek sudah memiliki web resmi untuk kehadiran, sedangkan pegawai non-PNS masih belum tersedia. Penerapan kehadiran untuk pegawai non-PNS sudah menggunakan mesin kehadiran fingerprint, namun pengolahannya masih dilakukan secara manual. Keluaran dari aplikasi bawaan mesin fingerprint tidak dapat diubah sesuai kebutuhan. Maka dari itu, setiap periodenya pengolah harus mengolah kehadiran melalui Microsoft Excel dengan memasukkan rumus ke dalamnya. Selain itu, pegawai sulit untuk melihat kehadiran pegawai karena belum ada web yang menampilkan kehadiran. Pegawai juga kesulitan dalam melengkapi data keterangan izin dan cuti.

Diperlukan sistem yang memudahkan pengolah dalam mengolah kehadiran pegawai non-PNS dan memudahkan pegawai dalam memeriksa kehadiran, melakukan pelengkapan data izin, dan data cuti. Sistem ini diharapkan memiliki fitur pengelolaan data pegawai, pemasukan data kehadiran oleh admin, pelengkapan data izin, pelengkapan data cuti, serta rekapitulasi data.

Tujuan dibuatnya sistem informasi kehadiran ini di antaranya untuk menyediakan fitur pengelolaan data kehadiran pegawai, fitur kehadiran pegawai, fitur kelengkapan data izin, dan fitur kelengkapan data cuti.

\section{METODE PENELITIAN}

Pembuatan sistem menggunakan metode incremental. Alasan 
penggunaan metode ini karena metode pengembangannya sederhana, resiko kegagalannya lebih rendah, klien sudah mengetahui kebutuhan yang dibutuhkan, serta klien juga ikut andil dalam memberikan masukannya.

Metode incremental adalah pengembangan secara bertahap yang dilakukan dengan cara membagi ke dalam subsistem yang bisa berjalan secara paralel. Menurut Roger Pressman (Pressman 2010) terdapat lima tahapan yang dilakukan, yaitu: 1) komunikasi, 2) perencanaan, 3) pemodelan, 4) pembuatan, dan 5) penyebaran. Berdasarkan Gambar 2, lima tahapan merupakan implementasi dari satu subsistem, yang nantinya tahapan-tahapan tersebut menjadi satu kesatuan yang membentuk increment 1, increment 2, dan seterusnya. Tahapan metode incremental dapat dilihat pada Gambar 1.

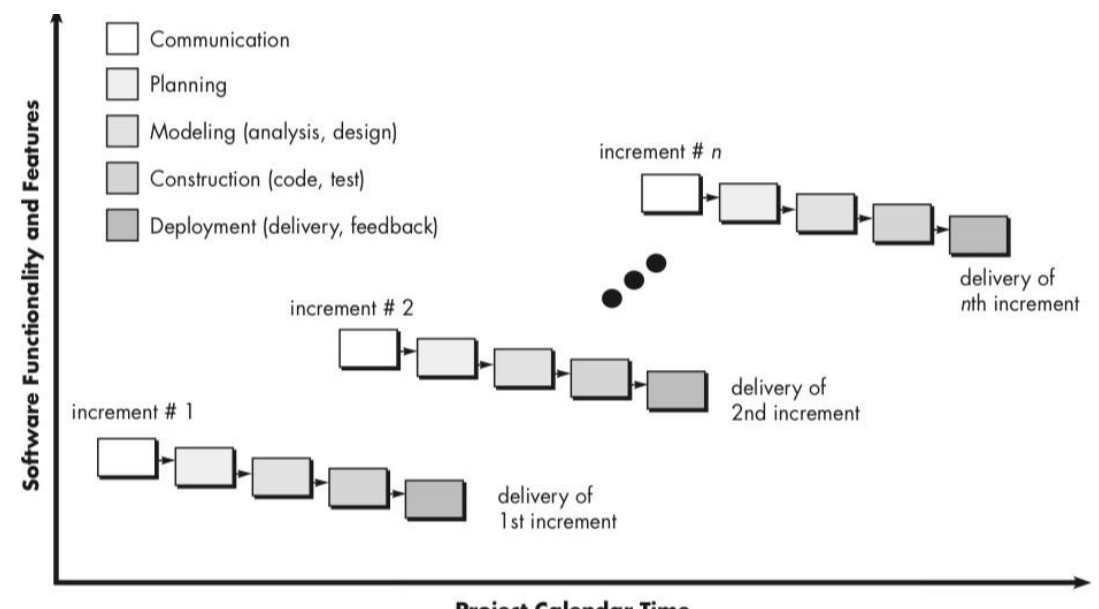

Gambar 1 Tahapan metodologi incremental (Pressman2010)

Tahapan pertama komunikasi antara pengguna dan pengembang. Tahap ini harus dilakukan sebelum melakukan analisis, pemodelan, atau spesifikasi (Pressman 2010). Pengguna memiliki masalah yang bisa diselesaikan dengan sistem berbasis komputer, maka dilakukan komunikasi agar pengembang bisa mendapatkan sasaran yang akan dicapai, memahami masalah, dan menentukan kebutuhan apa saja yang dapat membantu memahami fungsi dan fitur sistem.

Tahapan kedua dibuat suatu perencanaan sistem serta batasan ruang lingkupnya, meliputi manajemen dan praktek teknis yang memudahkan pengembang untuk menjabarkan road map dalam mencapai tujuan dan sasaran (Pressman 2010). Perencanaan dilakukan dengan cara membuat rencana tugas- tugas yang hendak dikerjakan, kebutuhan, produk yang dihasilkan, dan jadwal.

Tahap ketiga pemodelan, untuk mempermudah memahami kebutuhan secara menyeluruh. Standar pemodelan yang digunakan adalah Unified Modeling Language (UML) yaitu menggunakan use case diagram, class diagram, dan activity diagram. Diagram-diagram ini membantu dalam menyelaraskan spesifikasi kebutuhan.

Tahapan keempat adalah pembuatan, proses menghasilkan increment berdasarkan pemodelan yang telah dibuat sebelumnya. 
Tujuannya untuk mendefinisikan spesifikasi kebutuhan. Aktivitas mencangkup kegiatan penulisan kode dan uji perangkat lunak hingga siap diberikan kepada klien.

Tahapan kelima adalah penyebaran, sistem yang telah dibuat akan diberikan kepada klien atau pengguna, kemudian pengguna akan mengevaluasi apakah sudah sesuai dengan kebutuhan fungsional atau belum. Setelah mengevaluasi, pengguna akan memberikan feedback terhadap sistem yang sudah dibuat.

\section{HASIL DAN PEMBAHASAN}

Pembuatan sistem menghasilkan dua iterasi increment, yaitu increment pertama dan increment kedua. Increment pertama menghasilkan 22 fungsi dan increment kedua menghasilkan 28 fungsi baru.

\section{Increment pertama}

\subsection{Komunikasi}

Pusyantek BPPT memiliki jadwal masuk dan keluar yang berbeda pada hari kerja Senin sampai Jumat. Hari Senin sampai dengan Kamis pegawai masuk pukul 07.30 dan keluar pukul 16.00, dengan durasi kerja tujuh jam tiga puluh menit ditambah satu jam istirahat. Berbeda dengan hari jumat yang jam masuk pukul 07.30 dan keluar pukul 16.30, dengan durasi kerja tujuh jam tiga puluh menit ditambah satu setengah jam istirahat.

Proses kehadiran pegawai non PNS Pusyantek dimulai dengan tap jari ke mesin fingerprint, yaitu sebelum jam masuk dan sesudah jam keluar yang sudah ditentukan. Kemudian data kehadiran dari mesin masuk ke komputer yang sudah ada aplikasi mesin fingerprint. Pengolah mengolah data yang sudah tersimpan dalam dengan cara mengekspor data dalam format excel. Pengolah mengolah data pegawai satu persatu menggunakan Microsoft Excel dengan memasukkan rumus. Proses tersebut dilakukan satu per satu untuk 25 pegawai yang ada di Pusyantek setiap periode. Dalam satu file berisi 500 baris data kehadiran dan 29 kolom. Tentu hal ini menimbulkan beberapa masalah. yaitu menimbulkan data yang tidak akurat, pemanfaatan waktu yang tidak efisien, dan lain-lain.

Dengan adanya permasalahan di atas, pengolah mengharapkan adanya aplikasi berbasis website yang memudahkan pengolah dalam mengolah data kehadiran. Pengolah pun berharap agar pegawai dapat dengan mudah mengakses kehadiran, mengajukan izin, dan mengajukan cuti. Sistem yang diharapkan pengolah adalah pengolah bisa langsung mengunggah file data kehadiran ke dalam sistem dan sistem akan langsung mengolah secara otomatis kolom apa saja yang diperlukan tanpa harus diolah terlebih dahulu.

\subsection{Perencanaan}

Tahap ini dilakukan untuk menganalisis kebutuhan dan masalah untuk mendapatkan fungsi yang akan dikembangkan. Penamaan kode untuk kebutuhan adalah SIAP-XXX singkatan dari kode fungsi, representasi dari kebutuhan fungsional dan SIAP-XXX-X kebutuhan sub-fungsional, SIAP diambil dari nama sistem. Kebutuhan data dapat dilihat pada Tabel 1 , 
kebutuhan fungsional pada Tabel 2, dan kebutuhan non fungsional pada Tabel 3.

Tabel 1 Analisis kebutuhan data increment satu

\begin{tabular}{llll}
\hline Nama & Primary & Store & Deskripsi \\
\hline Absensi & Absensi_id & siap & Berisi informasi data kehadiran pegawai \\
Bulan & Bulan_id & siap & Berisi informasi periode bulan \\
Cuti & Cuti_id & siap & Berisi informasi pengajuan cuti pegawai \\
Izin & Izin_id & siap & Berisi informasi pengajuan izin pegawai \\
Jabatan & Jabatan_id & siap & Berisi informasi jabatan pegawai \\
Lampiran & Lampiran_id & siap & Berisi lampiran pengajuan izin dan cuti \\
Pegawai & Peg_no_akun & siap & Berisi informasi data pegawai \\
Tahun & Tahun_id & siap & Berisi informasi periode tahun \\
User & Username & siap & Berisi informasi user \\
\hline
\end{tabular}

Tabel 2 Analisis kebutuhan fungsional increment satu

\begin{tabular}{lll}
\hline Kode & Fungsional & \multicolumn{1}{c}{ Deskripsi } \\
\hline SIAP-001 & Login & Pegawai, admin melakukan login \\
SIAP-002 & Logout & Pegawai, admin melakukan logout \\
SIAP-003 & Lihat absensi & Pegawai melihat daftar kehadiran \\
SIAP-004 & Kelola pengajuan izin & Pegawai mengelola pengajuan izin \\
SIAP-004-1 Lihat pengajuan izin & Pegawai melihat pengajuan izin \\
SIAP-004-2 Tambah pengajuan izin & Pegawai menambah pengajuan izin \\
SIAP-004-3 Ubah pengajuan izin & Pegawai mengubah pengajuan izin \\
SIAP-004-4 Hapus pengajuan izin & Pegawai menghapus pengajuan izin \\
SIAP-004-5 Cetak pengajuan izin & Pegawai mencetak pengajuan izin \\
SIAP-005 Kelola pengajuan cuti & Pegawai mengelola pengajuan cuti \\
SIAP-005-1 Lihat pengajuan cuti & Pegawai melihat pengajuan cuti \\
SIAP-005-2 Tambah pengajuan cuti & Pegawai menambah pengajuan cuti \\
SIAP-005-3 Ubah pengajuan cuti & Pegawai mengubah pengajuan cuti \\
SIAP-005-4 Hapus pengajuan cuti & Pegawai menghapus pengajuan cuti \\
SIAP-005-5 Cetak pengajuan cuti & Pegawai mencetak pengajuan cuti \\
SIAP-006 Kelola persetujuan & Pegawai mengelola persetujuan \\
SIAP-006-1 Unggah persetujuan & Pegawai mengunggah persetujuan \\
SIAP-006-2 Hapus persetujuan & Pegawai menghapus persetujuan \\
SIAP-007 Kelola profil pegawai & Pegawai mengelola profil \\
SIAP-007-1 Ubah username & Pegawai mengubah username \\
SIAP-007-2 Ubah password & Pegawai mengubah password \\
SIAP-007-3 Ubah nama & Pegawai mengubah nama \\
\hline
\end{tabular}

Tabel 3 Analisis kebutuhan non fungsional increment satu

\begin{tabular}{lll}
\hline Kode & Parameter & \multicolumn{1}{c}{ Deskripsi } \\
\hline SIAP-008 & Communication & Bahasa Indonesia \\
SIAP-009 & Security & Hak akses \\
SIAP-010 & Availability & 24 jam sehari, 7 hari seminggu. \\
\hline
\end{tabular}




\subsection{Pemodelan}

\subsubsection{Use Case Diagram}

Pada incremental pertama didahulukan pengerjaan fungsi untuk user pegawai. Use case diagram dapat dilihat pada Gambar 2. Use case diagram dijabarkan dengan deskripsi use case, salah satunya dapat dilihat pada Tabel 4.

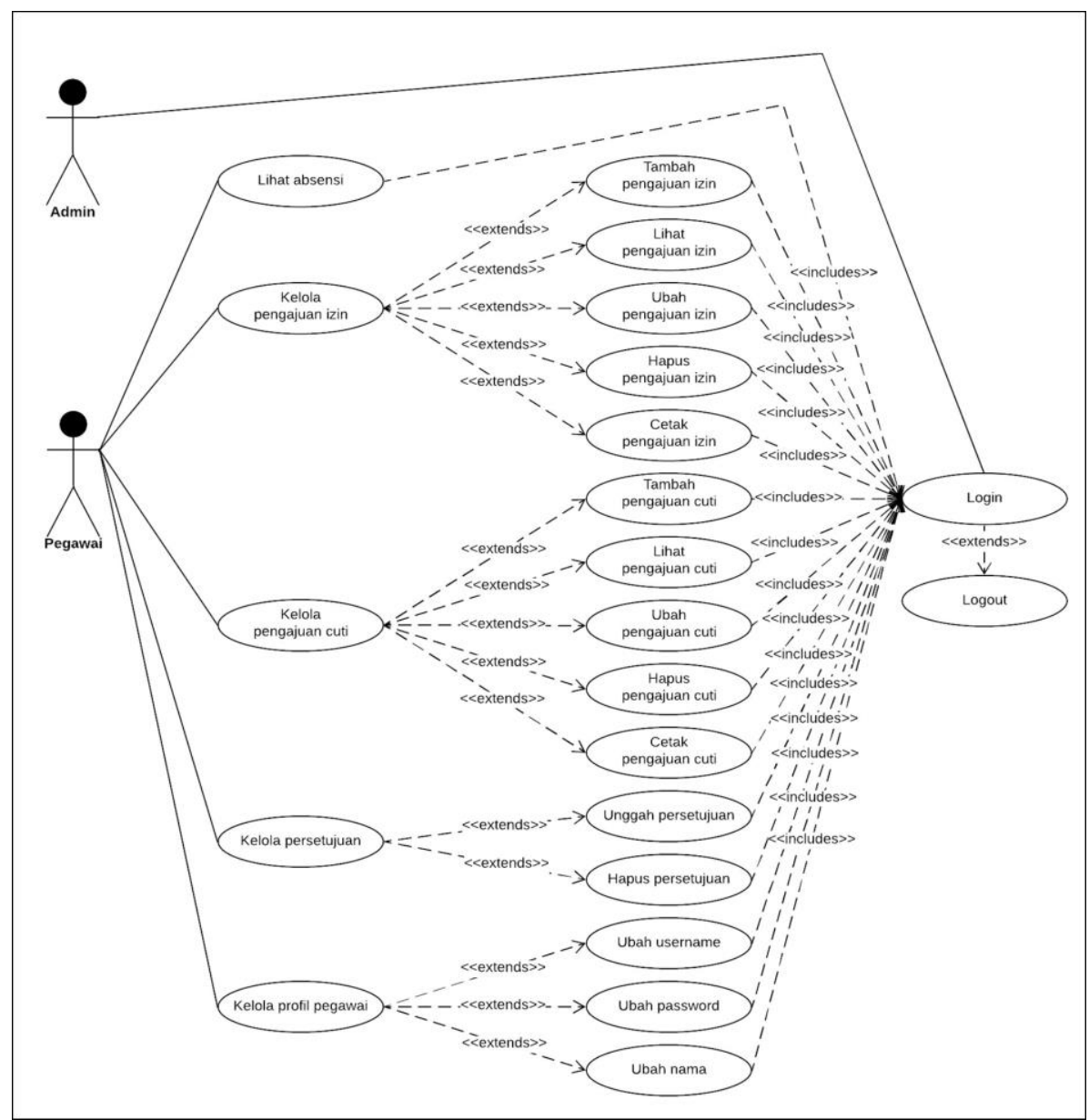

Gambar 2 Use case diagram increment satu

\subsubsection{Class Diagram}

Perancangan database untuk sistem yang akan dibuat menghasilkan suatu class diagram. Class diagram berisikan rancangan relasi antara tabel sudah dianalisis keperluannya untuk sistem, dapat dilihat pada Gambar 3.

\subsubsection{Antarmuka}

Rancangan antarmuka bertujuan untuk memberikan gambaran seperti apa tampilan yang akan dibuat, penempatan header dan konten pada sistem. Salah satu rancangan antarmuka, yaitu absensi pegawai dapat dilihat pada Gambar 4.

\subsubsection{Masukan}

Rancangan masukan bertujuan mendeskripsikan masukan agar meminimalisir kesalahan pada pemasukan data. Salah satu rancangan masukan, yaitu tambah pengajuan izin dapat dilihat pada Gambar 5. 


\subsubsection{Proses}

Rancangan proses adalah alur kerja dari use case yang sudah dibuat untuk menggambarkan aliran proses dan menghasilkan activity diagram. Salah satu activity diagram untuk sistem ini dapat dilihat pada Gambar 6 .

\subsubsection{Keluaran}

Rancangan keluaran dihasilkan dari activity diagram yang sudah dibuat sebelumnya. Rancangan keluaran berfungsi untuk menggambarkan hasil dari proses yang akan ditampilkan oleh sistem.

Tabel 4 Deskripsi use case tambah pengajuan izin di increment satu

\begin{tabular}{|c|c|}
\hline Use Case & (n) \\
\hline Use Case Name & Tambah pengajuan izin \\
\hline Goal in Context & $\begin{array}{l}\text { Pegawai bisa menambahkan pengajuan izin } \\
\text { dengan mengisi form yang sudah ada }\end{array}$ \\
\hline Precondition & $\begin{array}{l}\text { Masuk ke halaman pengajuan izin dengan } \\
\text { periode default bulan dan tahun sekarang }\end{array}$ \\
\hline Successful End Condition & $\begin{array}{l}\text { Pegawai berhasil menambah pengajuan izin, } \\
\text { selanjutnya system akan menampilkan data } \\
\text { yang baru ditambahkan ke daftar data } \\
\text { pengajuan izin }\end{array}$ \\
\hline Failed End Condition & $\begin{array}{l}\text { Muncul warning untuk mengisi field yang } \\
\text { kosong }\end{array}$ \\
\hline Actor & Pegawai \\
\hline Trigger & $\begin{array}{l}\text { Pegawai mengisi form yang berisi jenis, } \\
\text { tanggal sebelum, tanggal sesudah, dan } \\
\text { keterangan izin. Setelah selesai mengisi, } \\
\text { pegawai memilih simpan }\end{array}$ \\
\hline Main Flow & $\begin{array}{l}\text { 1. Menekan tombol tambah } \\
\text { 2. Mengisi jenis izin } \\
\text { 3. Mengisi tanggal sebelum dan sesudah } \\
\text { 4. Mengisi keterangan jika perlu } \\
\text { 5. Menekan tombol simpan atau batal }\end{array}$ \\
\hline Extension & $\begin{array}{l}\text { 1. Jika filed masih kosong, akan muncul } \\
\text { warning } \\
\text { 2. Jika menekan batal maka fungsi dibatalkan }\end{array}$ \\
\hline
\end{tabular}




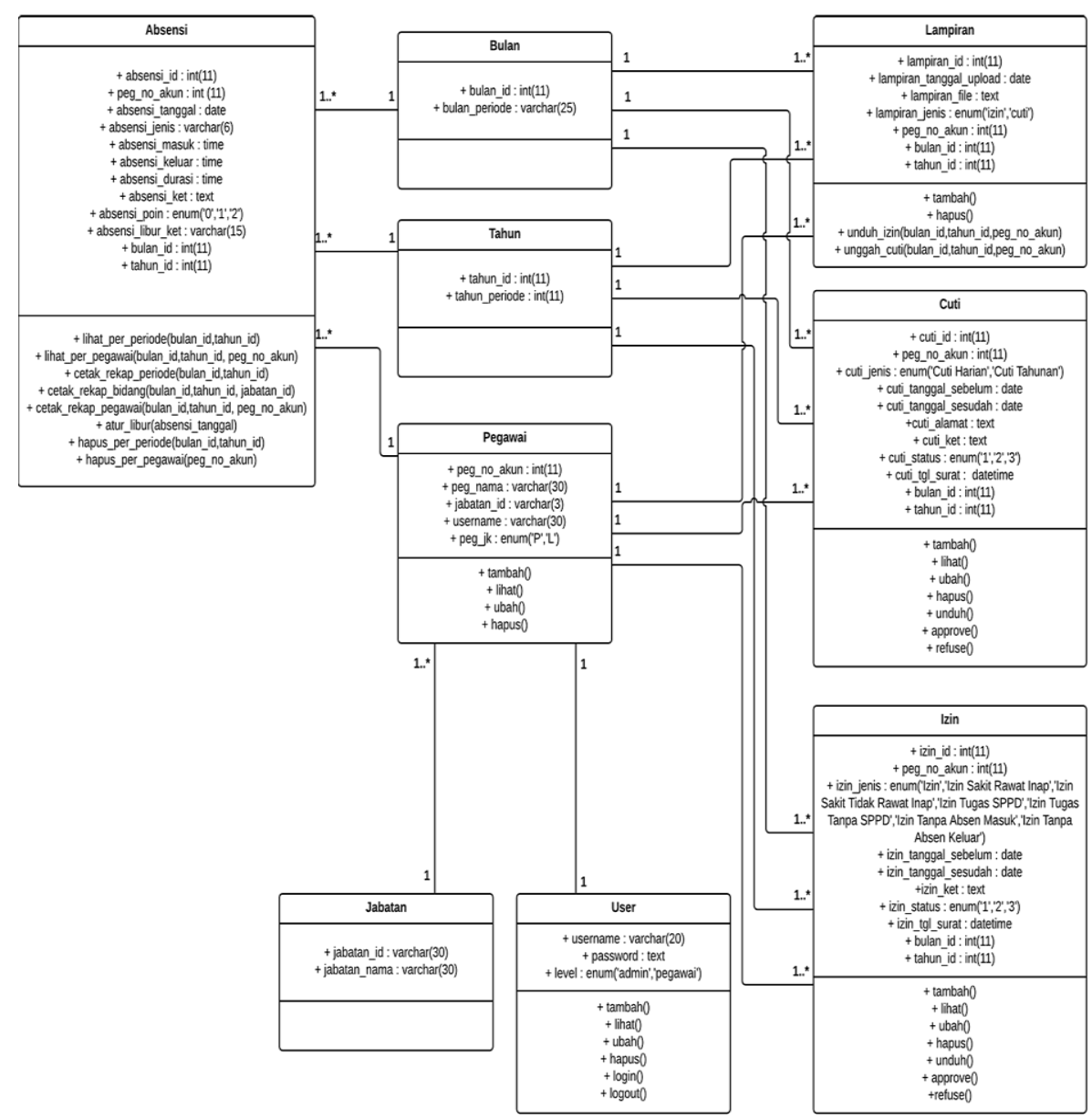

Gambar 3 Class diagram increment satu

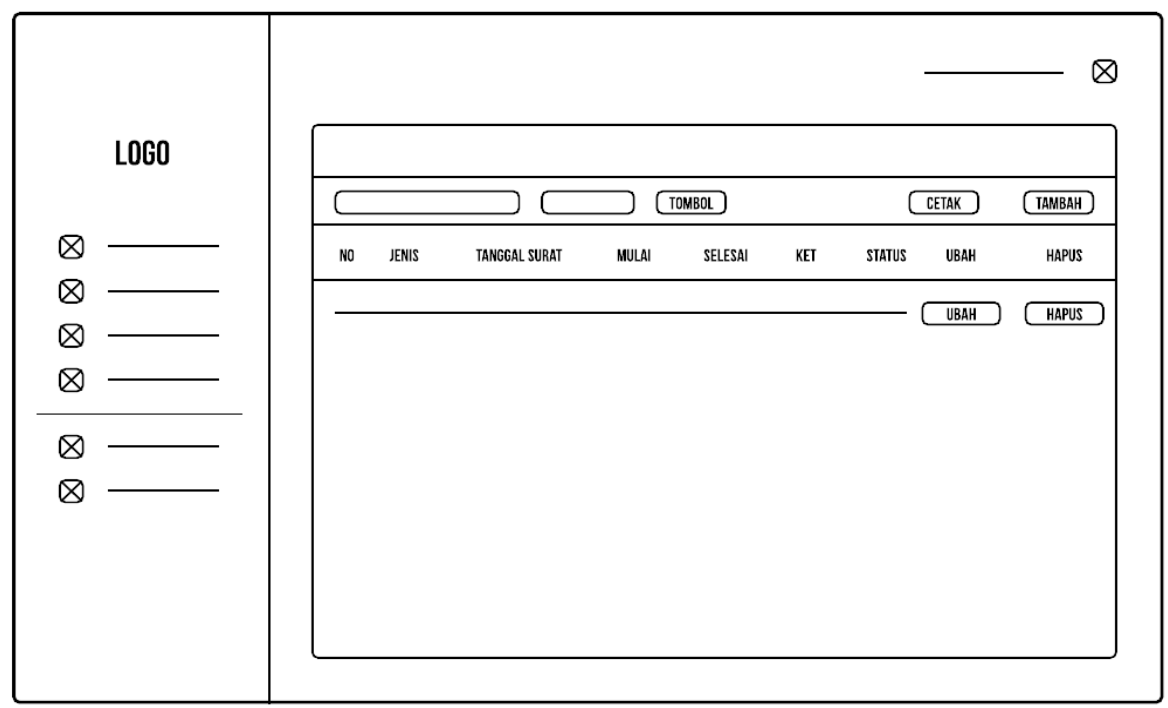

Gambar 4 Rancangan antarmuka pengajuan izin increment satu 


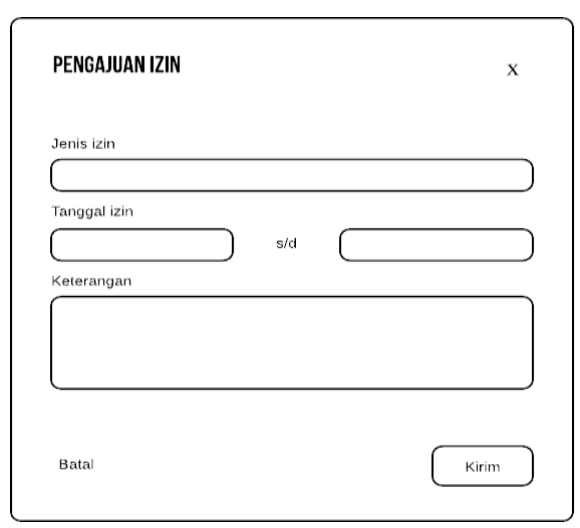

Gambar 5 Rancangan masukan tambah pengajuan izin increment satu

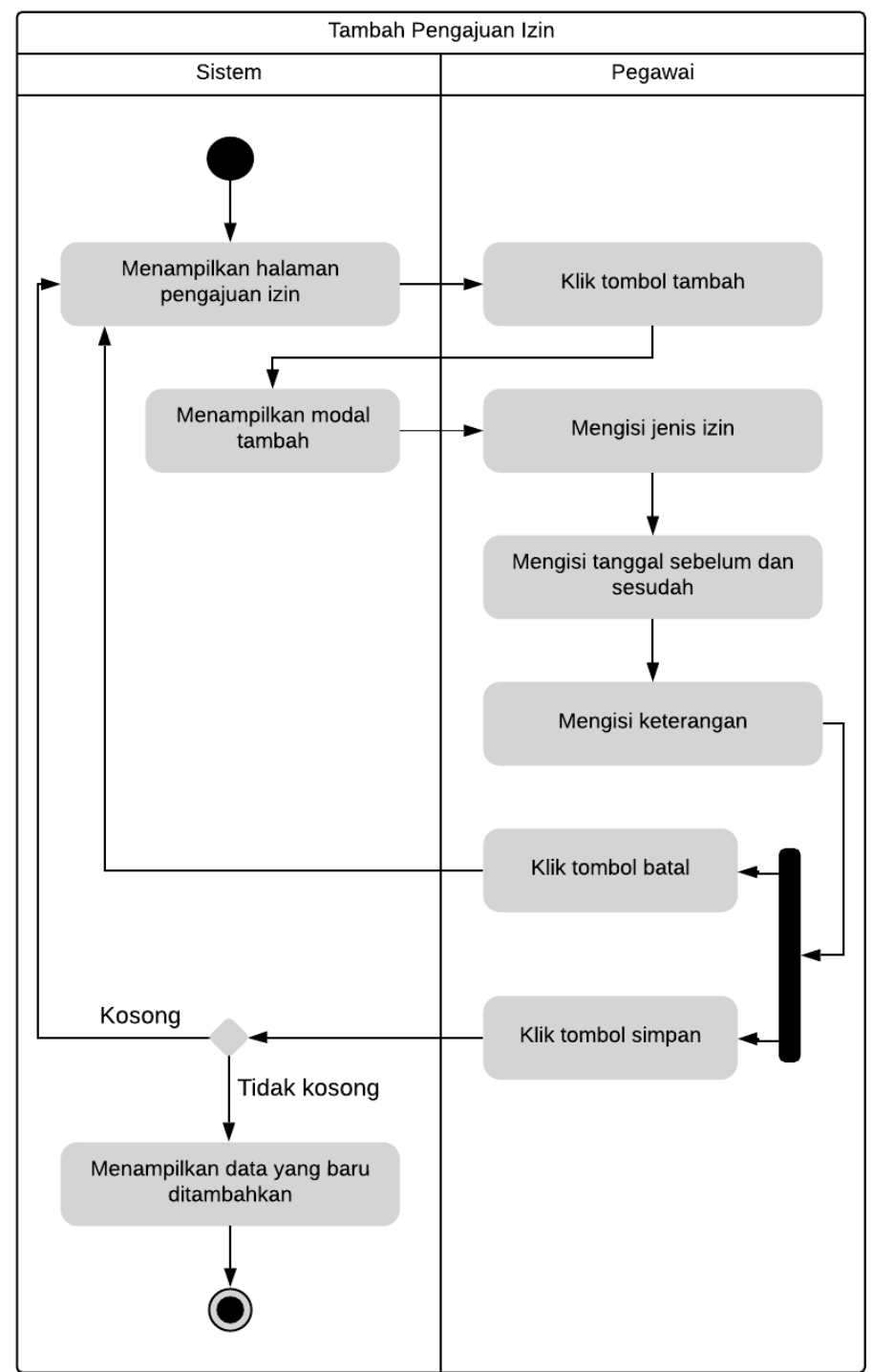

Gambar 6 Rancangan activity diagram tambah pengajuan izin 


\subsection{Pembuatan}

Pembuatan sistem menggunakan laptop Macbook Air. Perangkat lunak yang digunakan dalam pembuatan sistem ini, yaitu:

- Sistem operasi

: macOS High Sierra

- Bahasa pemrograman :PHP

- DBMS

- Web Server

: MySQL

- Framework

: Apache

- Web browser

: Codelgniter

- Text editor

: Google Chrome dan Safari

: Sublime Text

\subsubsection{Implementasi Database}

Tahap ini menghasilkan implementasi database berdasarkan kebutuhan data yang telah dibuat pada tahap pemodelan. Hasil implementasi dapat dilihat pada Gambar 7.

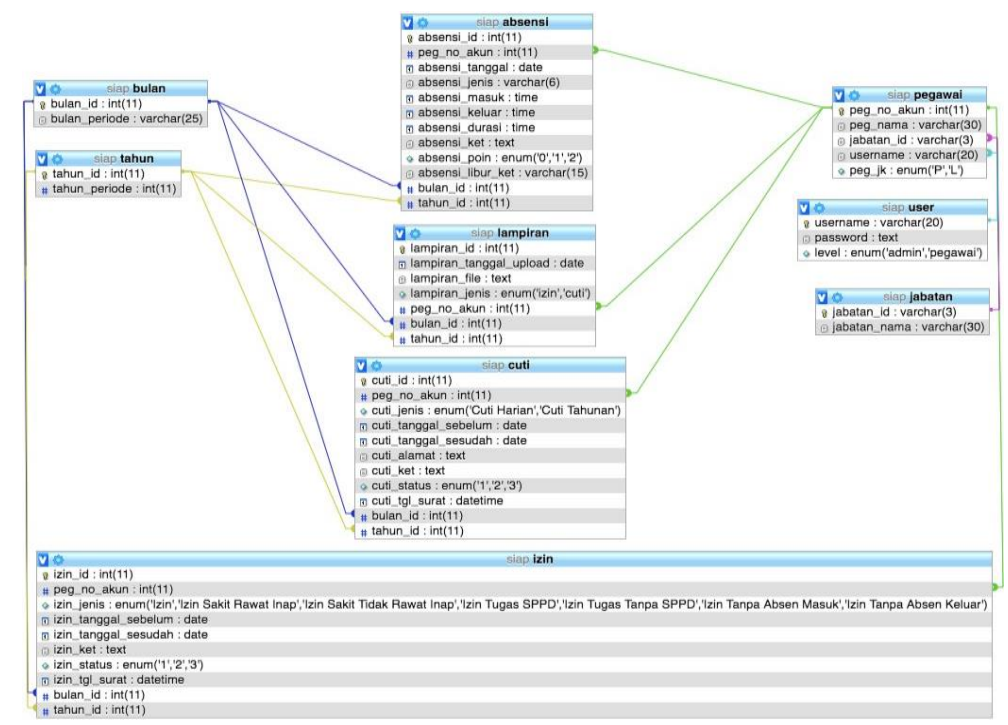

Gambar 7 Implementasi database

\subsubsection{Implementasi Antarmuka}

Tahapan implementasi antarmuka merupakan proses untuk menghasilkan implementasi dari antarmuka yang sudah dibuat sebelumnya dengan melakukan pengkodean. Implementasi antarmuka absensi dapat dilihat pada Gambar 8.

\subsubsection{Implementasi Masukan}

Tahapan implementasi masukan merupakan proses menghasilkan masukan yang sudah dirancang sebelumnya. Salah satu implementasi masukan, yaitu implementasi tambah pengajuan izin dapat dilihat pada Gambar 9.

\subsubsection{Implementasi Proses}

Tahapan implementasi proses untuk sistem ini menggunakan bantuan dari framework Codelgniter dengan bahasa pemrograman PHP dan editor Sublime Text. Framework Codelgniter menggunakan pola yang bernama model-view- controller, dimana pada proses implementasinya melakukan pengkodean yang dipisahkan menjadi model, view, dan controller. 


\subsubsection{Implementasi Keluaran}

Implementasi keluaran pada sistem ini menghasilkan keluaran berupa tabel dan laporan rekap berformat PDF. Salah satu implementasi keluaran, yaitu implementasi keluaran absensi dapat dilihat pada Gambar 10.
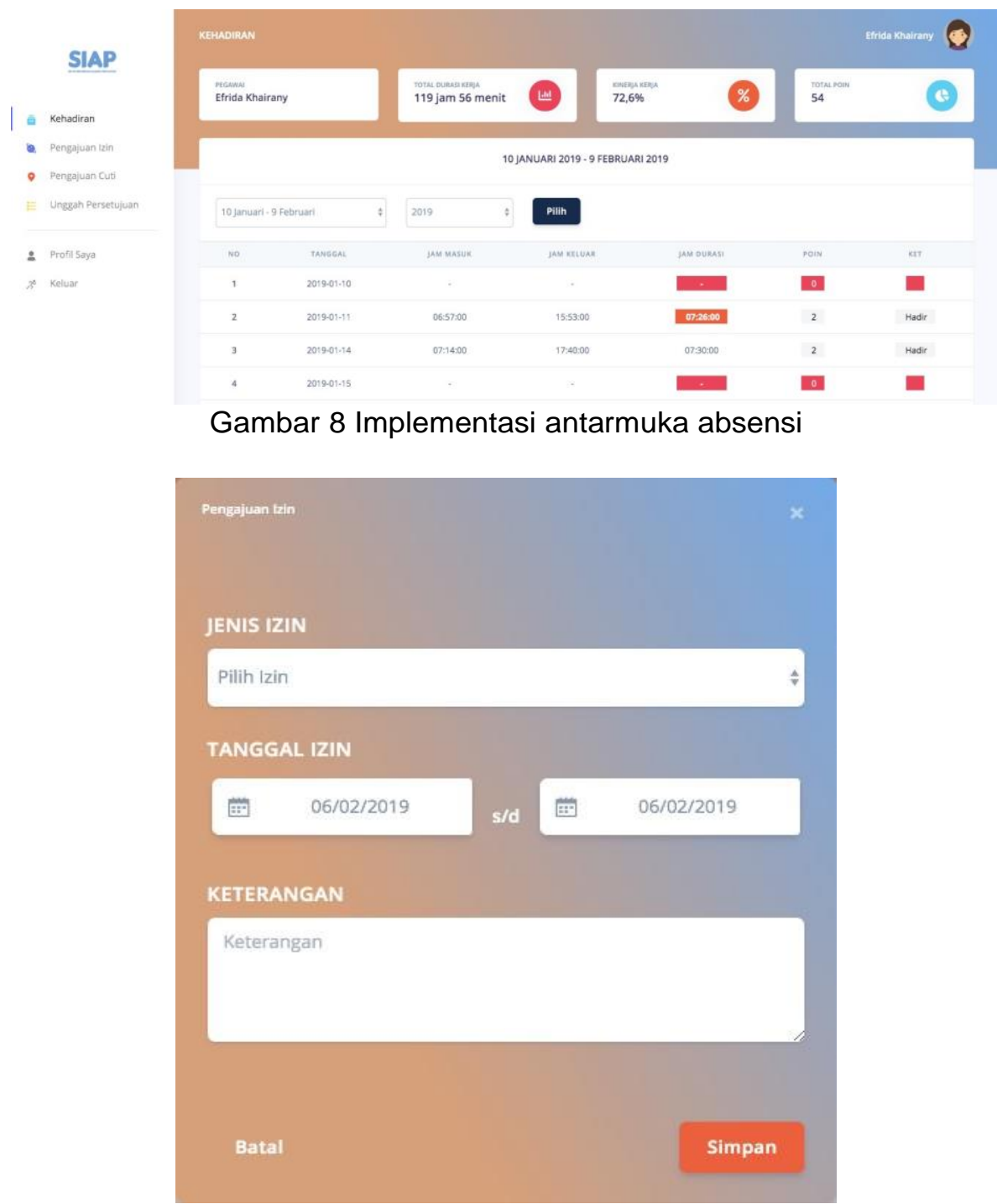

Gambar 9 Implementasi masukan tambah pengajuan izin

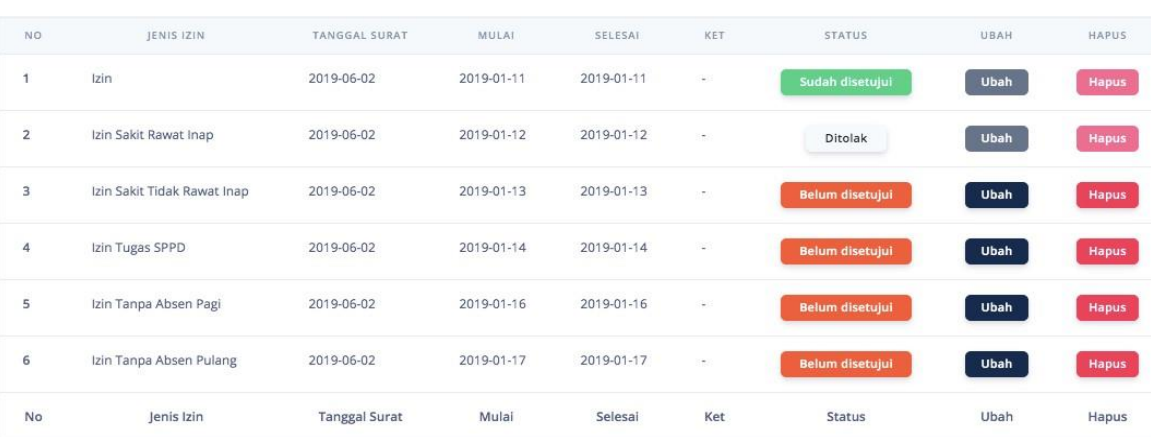

Gambar 10 Implementasi keluaran pengajuan izin 


\subsection{Penyebaran dan Umpan Balik}

Pada tahap ini dilakukan presentasi di hadapan klien berupa demo sistem yang berguna untuk pengujian terhadap sistem. Pengujian bertujuan untuk mencari kesalahan saat menjalankan sistem. Pengujian pada tahap ini menggunakan metode black box. Pengujian login dapat dilihat pada Tabel 5 .

Tabel 1 Pengujian fungsi login di increment satu

\begin{tabular}{|c|c|c|c|}
\hline $\begin{array}{c}\text { Nilai } \\
\text { Masukan }\end{array}$ & Skenario Pengujian & $\begin{array}{l}\text { Hasil yang } \\
\text { Diharapkan }\end{array}$ & Hasil \\
\hline Benar & $\begin{array}{l}\text { Pengguna mengisi form } \\
\text { dengan masukan yang benar, } \\
\text { klik masuk }\end{array}$ & $\begin{array}{l}\text { Berhasil masuk } \\
\text { sesuai hak akses }\end{array}$ & Sukses \\
\hline Salah & $\begin{array}{l}\text { Pengguna mengisi form } \\
\text { dengan masukan username } \\
\text { atau password salah, klik } \\
\text { masuk }\end{array}$ & $\begin{array}{l}\text { Gagal masuk, } \\
\text { muncul alert }\end{array}$ & Sukses \\
\hline Kosong & $\begin{array}{l}\text { Pengguna tidak mengisi form, } \\
\text { klik tombol masuk }\end{array}$ & $\begin{array}{l}\text { Muncul alert jika } \\
\text { form kosong }\end{array}$ & Sukses \\
\hline $\begin{array}{l}\text { Username } \\
\text { kosong }\end{array}$ & $\begin{array}{l}\text { Pengguna mengisi form } \\
\text { dengan username kosong dan } \\
\text { password terisi, klik tombol } \\
\text { masuk }\end{array}$ & $\begin{array}{l}\text { Muncul alert jika } \\
\text { username kosong }\end{array}$ & Sukses \\
\hline $\begin{array}{l}\text { Password } \\
\text { kosong }\end{array}$ & $\begin{array}{l}\text { Pengguna mengisi form } \\
\text { dengan username terisi dan } \\
\text { password kosong, klik tombol } \\
\text { masuk }\end{array}$ & $\begin{array}{l}\text { Muncul alert jika } \\
\text { password kosong }\end{array}$ & Sukses \\
\hline
\end{tabular}

2. Increment kedua

2.1 Komunikasi

Pada tahap ini dilakukan konsultasi lanjutan mengenai fungsi tambahan yang hendak dibuat pada increment kedua. Sistem yang diharapkan pengolah yaitu pengolah dapat langsung mengunggah file data kehadiran ke dalam sistem dan sistem akan langsung mengolah secara otomatis kolom apa saja yang diperlukan tanpa harus diolah. Setelah melalui beberapa kali konsultasi didapatkan kesimpulan kebutuhan yang diinginkan oleh klien. Berikut fitur yang diharapkan pengolah:

- Pengolah dapat mengekspor file kehadiran ke sistem dalam format .xlsx.

- Pengolah dapat melihat data kehadiran pegawai per periode (hari, tanggal, jam masuk, jam keluar, durasi, poin, dan keterangan.)

- Pengolah dapat melihat dan mencetak rekap kehadiran (nama pegawai, jumlah masuk, sakit, izin, cuti, tanpa keterangan, tidak lengkap, SPPD, tanpa SPPD, total durasi, kinerja kerja, dan poin) tiap periode.

- $\quad$ Pengolah menyetujui atau menolak pengajuan izin dan cuti yang dibuat. 


\subsection{Perencanaan}

Pada tahap perencanaan increment kedua, didapatkan analisis kebutuhan data untuk user admin yang berjumlah 28 fungsi. Berikut adalah hasil yang didapatkan dari tahap komunikasi yang dilakukan pada tahap sebelumnya. Pada kebutuhan data, ditambahkan satu tabel bernama upload_absensi yang berguna untuk menyimpan data unggah absensi periode, dapat dilihat pada Tabel 6. Kebutuhan fungsional pada sistem kehadiran dapat dilihat pada Tabel 7.

Tabel 6 Analisis kebutuhan data di increment dua

\begin{tabular}{cccc}
\hline Nama & Primary & Store & Deskripsi \\
\hline Upload_absensi & Upload_id & siap & Informasi unggahan absensi periode \\
\hline
\end{tabular}

Tabel 7 Analisis kebutuhan fungsional di increment dua

\begin{tabular}{|c|c|c|}
\hline Kode & Fungsional & Deskripsi \\
\hline SIAP-011 & Kelola data absensi & Admin mengelola data kehadiran \\
\hline SIAP-011-1 & Unggah data absensi & Admin mengimport data kehadiran \\
\hline SIAP-011-2 & Hapus absensi periode & $\begin{array}{l}\text { Admin menghapus } \\
\text { periode }\end{array}$ \\
\hline SIAP-011-3 & Hapus absensi pegawai & $\begin{array}{l}\text { Admin menghapus } \\
\text { pegawai }\end{array}$ \\
\hline SIAP-011-4 & Lihat absensi per periode & Admin melihat data kehadiran \\
\hline SIAP-011-5 & Lihat absensi per pegawai & Admin melihat data kehadiran \\
\hline SIAP-012 & Persetujuan pengajuan izin & Admin mengelola pengajuan cuti \\
\hline SIAP-012-1 & Approve pengajuan izin & Admin menyetujui pengajuan cuti \\
\hline SIAP-012-2 & Refuse pengajuan izin & Admin menolak pengajuan cuti \\
\hline SIAP-012-3 & pengajuan izin & Admin mengunduh pengajuan cuti \\
\hline SIAP-013 & Persetujuan pengajuan cuti & Admin mengelola pengajuan cuti \\
\hline SIAP-013-1 & e pengajuan cuti & Admin menyetujui pengajuan cuti \\
\hline SIAP-013-2 & uan cuti & Admin menolak pengajuan cuti \\
\hline SIAP-013-3 & pengajuan cutu & Admin mengunduh pengajuan cuti \\
\hline SIAP-014 & Kelola data pegawai & Admin mengelola data pegawai \\
\hline SIAP-014-1 & Lihat pegawai & Admin menilai pegawai \\
\hline SIAP-014-2 & h pegawai & Admin menambah data pegawai \\
\hline SIAP-014-3 & jegawai & Admin mengubah data pegawai \\
\hline SIAP-014-4 & ername pegawai & Admin mengubah username \\
\hline SIAP-014-5 & Jegawai & Admin menghapus pegawai \\
\hline SIAP-015 & Cetak rekap & Admin mencetak rekap \\
\hline SIAP-015-1 & rekap periode & $\begin{array}{l}\text { Admin mencetak rekap per } \\
\text { periode }\end{array}$ \\
\hline SIAP-015-2 & Cetak rekap bidang & Admin mencetak rekap per bidang \\
\hline SIAP-015-3 & Cetak rekap pegawai & $\begin{array}{l}\text { Admin mencetak rekap per } \\
\text { pegawai }\end{array}$ \\
\hline SIAP-016 & Atu & Admin mengatur hari libur \\
\hline SIAP-017 & Kelola profil ac & Admin mengelola profil admin \\
\hline SIAP-017-1 & Ubah username & Admin mengubah username \\
\hline SIAP-017-2 & Ubah password & Admin mengubah password \\
\hline
\end{tabular}




\subsection{Pemodelan}

Pada tahap pemodelan, dilakukan pemodelan kembali untuk iterasi yang kedua. Pada pemodelan iterasi kedua ditambahkan beberapa fungsi baru. Fungsi baru yang telah dianalisis sebelumnya dibentuk menjadi class diagram, antarmuka, masukan, proses dalam bentuk activity diagram, dan keluaran. Use case diagram untuk increment kedua dapat dilihat pada Gambar 12. Class diagram untuk inrement kedua mengakibatkan bertambahnya satu tabel, yaitu tabel upload_absensi. Class diagram dapat dilihat pada Gambar 13.

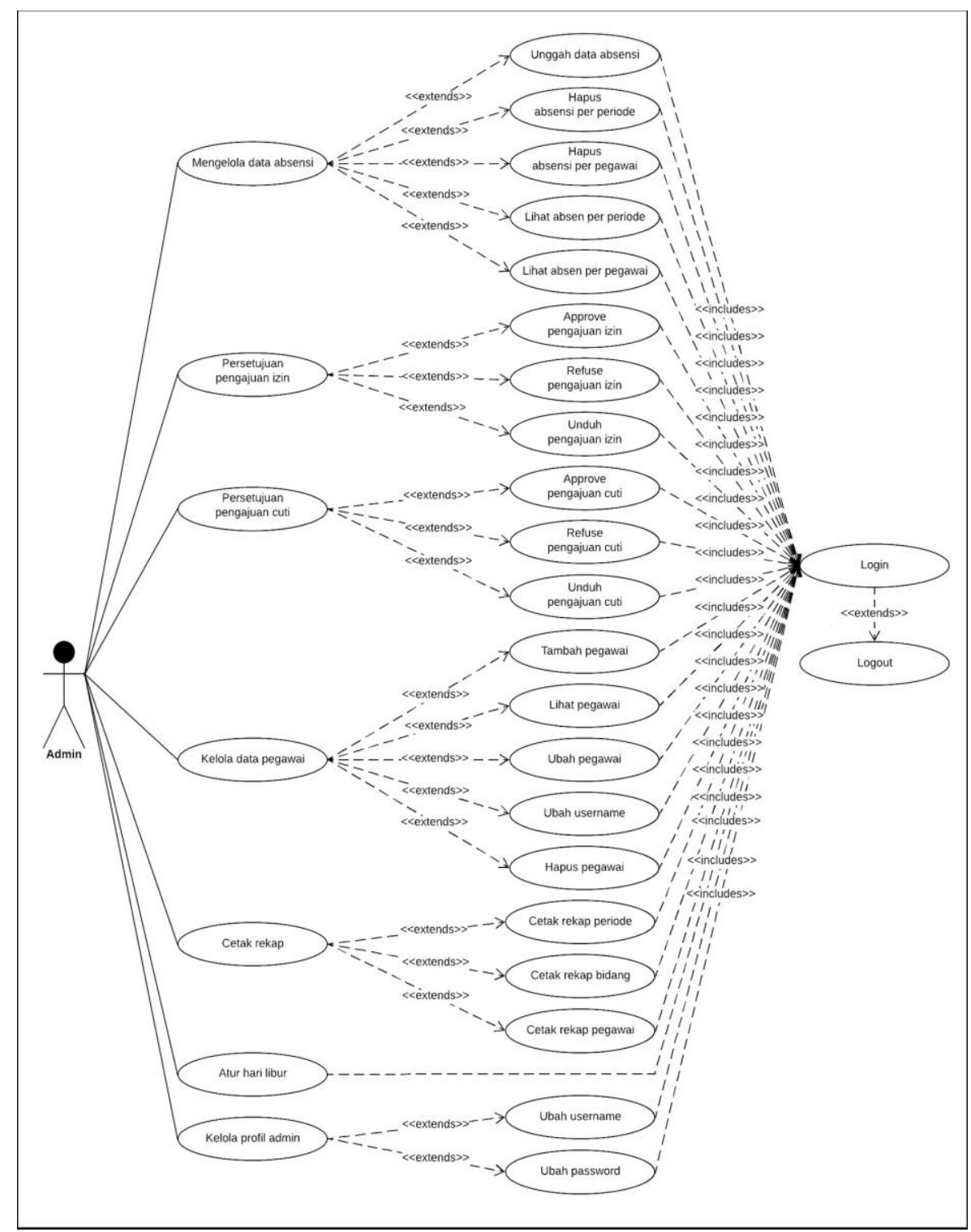

Gambar 11 Use case diagram increment dua 


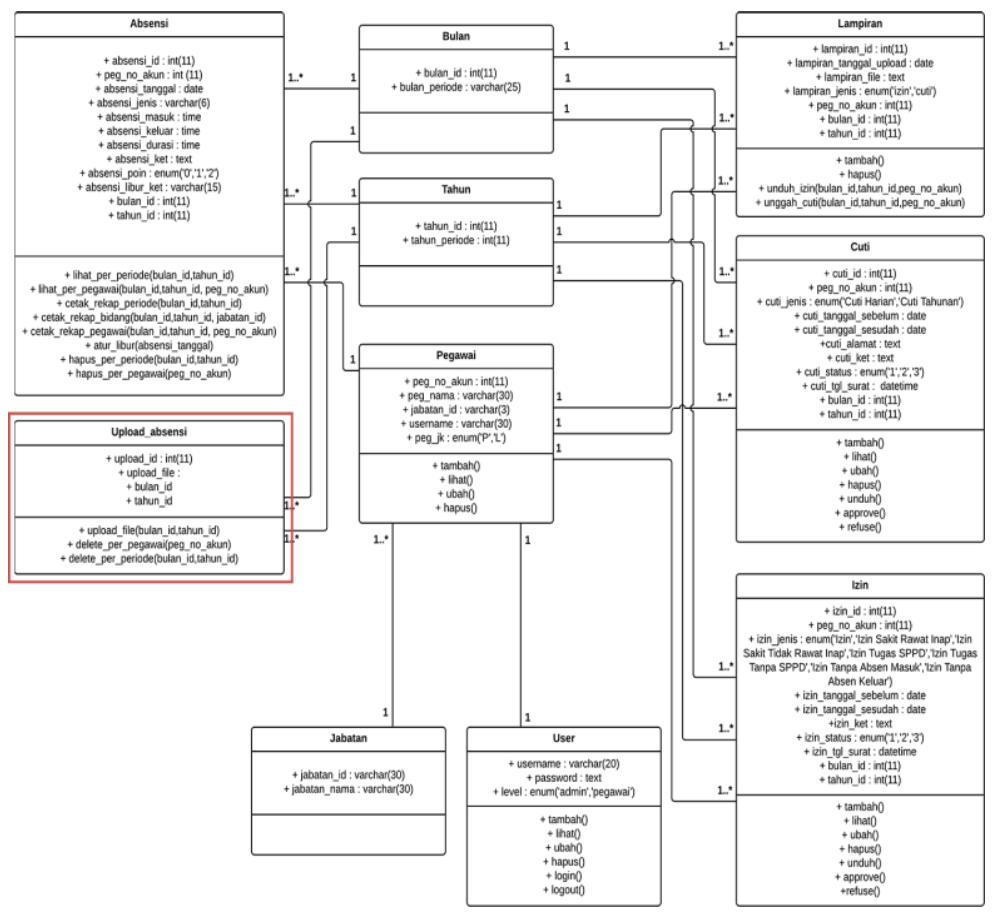

Gambar 12 Class diagram increment dua

\subsection{Pembuatan}

Sama seperti pada inrement pertama, dilakukan implementasi untuk database, proses, antarmuka, masukan, proses, dan keluaran. Implementasi pada database mengakibatkan penambahan tabel baru yaitu upload_absensi yang dapat dilihat pada Gambar 14.

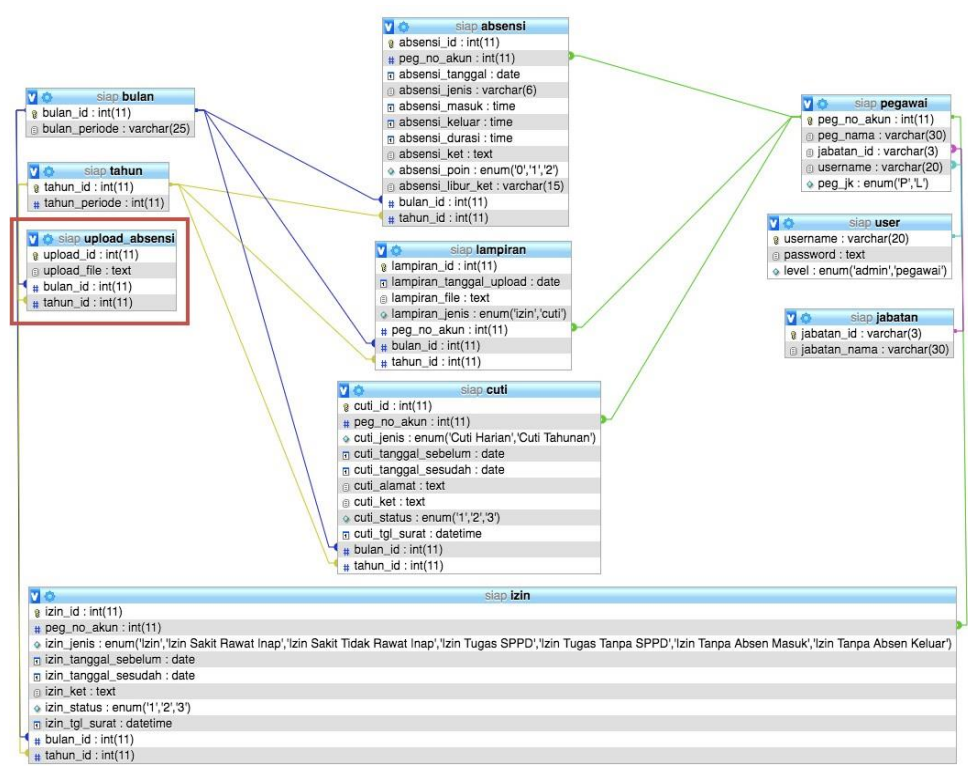

Gambar 13 Implementasi database increment dua

\subsection{Penyebaran dan Umpan Balik}

Pada tahap ini juga dilakukan presentasi di hadapan klien berupa demo sistem untuk pengujian terhadap sistem seperti pada increment pertama. 


\section{SIMPULAN}

Sistem Informasi Kehadiran Pegawai Non-PNS di Pusyantek BPPT merupakan sistem informasi yang mencakup kebutuhan kehadiran pegawai non- PNS. Setelah melewati tahap metode incremental, dapat disimpulkan bahwa fitur pengelolaan data kehadiran pegawai, fitur kehadiran pegawai, fitur kelengkapan data izin, dan fitur kelengkapan data cuti berhasil dibuat.

\section{SARAN}

Saran untuk sistem informasi kehadiran pegawai yaitu agar sistem dapat langsung terhubung dengan mesin fingerprint. Dengan demikian, pengolah tidak perlu mengunggah file data kehadiran ke dalam sistem secara manual. Sistem ini tidak menutup kemungkinan untuk dapat dikembangkan dengan menambahkan fitur yang lebih kompleks ke depannya.

\section{DAFTAR PUSTAKA}

Brand AW. 2013. PHP, MySQL, Javascript \& HTML5 All-In-One For Dummies. New Jersey(US): John Wiley \& Sons.

Codelgniter. Welcome to Codelgniter [Internet]. [Diunduh 2019 Februari 17]. Tersedia pada: www.codeigniter.com/user_guide/general/welcome.html. Codelgniter. Model-View-Controller [Internet]. [Diunduh 2019 Juni 12]. Tersedia pada: www.codeigniter.com/user_guide/overview/mvc.html.

Miles R, Hamilton K. 2006. Learning UML 2.0. United States of America(US) :

O’Reilly Media, Inc. 